\title{
Ecological Indicators for Landscape Assessment- Moving Forward with Sustainability Initiatives for Qatar
}

\author{
Hatem Galal A Ibrahim ${ }^{1,2 *}$
}

${ }^{1}$ Department of Architecture and Urban Planning, College of Engineering, Qatar University, Doha- Qatar

${ }^{2}$ Department of Architecture, College of Engineering, Helwan University, Cairo- Egypt

\begin{abstract}
According to the Central Intelligence Agency, Oil and gas have made Qatar the second highest per-capita income country - following Liechtenstein. The economy of Qatar is one of the active economies in the Middle East with a rapid growth in the construction sector. Since the mid-1980's; there has been a major breakthrough in the economic situation. The recent infrastructure boom and economic growth has revealed that Qatar is among the countries with the highest water consumption per capita. According to (Public Health Trade Mission, 2010) Qatar consumes over 219 million gallons of water per day, $99 \%$ of which comes from desalination plants with an expensive process of water treatment and water consumption. This consumption is expected to reach $\mathbf{3 8 0}$ million gallons per day by 2013. According to its geographical location and climate, Qatar is classified as a hot subtropical desert and has no rivers or lakes. The primary sources of fresh water are ground water and the Arabian Gulf. Surface water is very limited; it is only after a good winter rainfall that water may be found in depressions, wadis and runnels and then only for a short period of time.

In line with the previous and as the WWF Global article "Human demand outstrips nature's supply" cited; the footprint of high income countries is three times that of middle income countries and five times that of low income countries. It is clear that moving the development capacity forward is essential for increasing the economic system output in Qatar. Accordingly sustainable development has become more urgent in Qatar. However, managing for sustainability will be impossible without tools that allow us to account for our demand on and supply of; ecological resources for different variables of sustainability, including landscape ecology performance.
\end{abstract}

The paper intends to introduce a framework process for achieving an ecological landscape, sing implemented indicators based on Qatar's ecological variables. The introduced framework process includes:

1) Identifying policy and guidance.

2) Developing indicators.

3) Developing an appropriate monitoring program.

Keywords: Ecological landscape; Ecosystem classification; Landscape dynamics; Sustainable development; Qatar urban development

\section{Aim and Scope}

There are a number of significant challenges related to urban development which Qatar will face over the next few years. Landscape is still regarded as a largely visual matter and is often relegated to a secondary role as an urban design consideration. This phenomenon is unacceptable now as the role of the landscape is more beyond visual matter. Landscape is considered as the most important criteria for stainable urban development. To achieve an ecological landscape, it is necessary to develop a unique dialogue in context with the architecture and urban spaces.

Qatar's authorities are expressing efforts related to assessment landscape architecture such as: Qatar Sustainability Assessment System (QSAS) developed by BQDRI in collaboration with T.C. Chan Center at the University of Pennsylvania -USA. QSAS aims at assessing a sustainable urban environment to reduce the environmental impacts in general while satisfying local community needs. The landscape assessment in QSAS is located under Water Consumption as one of the green variables in the scheme. The aim of the paper is to develop landscape- based ecological assessment indicators, as an approach to developing a sustainability initiative in Qatar. These indicators emphasis the ecological landscape criteria to be integrated within the developed projects which are required to meet the environmental needs of the region, with minimal resource input. They comprise numerous practices related to the characteristics of Qatar.

\section{Case of Qatar}

Ecological footprint is an indicator of human pressure on nature, it measures how much land and water people need to produce the resources they consume and absorb the generated $\mathrm{CO}_{2}$. Biocapacity varies each year with; ecosystem management, agricultural practices, ecosystem degradation and weather. In Qatar, figure 1 shows how the ecological footprint is increasing and the biocapacity is continually decreasing.

Now that Qatar has state of the art technology, the country has become home to innumerable modern structures that have striking architectural designs which have modern interiors and stunning architectural design. It is highly likely that Qatar's successful 2022 world cup bid will accelerate large-scale urban, architecture and infrastructure projects. The integration of an ecologically sustainable landscape with contemporary architecture is needed. Additionally it requires a combination of a wide range of planning and conservation

*Corresponding author: Hatem Galal A Ibrahim, Department of Architecture and Urban Planning, College of Engineering, Qatar University, Doha- Qatar, E-mail: hatem_ibrahim@hotmail.com

Received October 11, 2012; Accepted November 19, 2012; Published November 21, 2012

Citation: Ibrahim HGA (2012) Descriptive Ecology Approaches to an Urban Landscape in Qatar. J Ecosyst Ecogr 2: 119. doi:10.4172/2157-7625.1000119

Copyright: (c) 2012 Ibrahim HGA. This is an open-access article distributed under the terms of the Creative Commons Attribution License, which permits unrestricted use, distribution, and reproduction in any medium, provided the original author and source are credited. 
management both at regional and local levels. In Qatar, the ecological component is crucial in landscape planning attached to the principles of sustainable development.

\section{Methodology}

The paper introduces a background about Qatar National Vision 2030, which aims at developing an advanced society, capable of sustaining development and providing a high standard of living. It is also analyzing the environmental contexts and their integration with the landscape architecture in Qatar. It reflects upon the degree to which Qatar were successful in fulfilling the key requirements of a landscape focusing on ecological assessment.

It is important to look at the integrated variables of the ecosystem according to the character of the country. This is why the second phase comes to define the implemented three steps of an ecological landscape framework for Qatar. The aim of this process is to formalize and conceptualize the key requirements based on a theoretical study. The key requirements are expected to confront some constraints during the identification and conceptual design such as, but not limited to; energy, materials and water. It gives an ecological indicator of what is needed for Qatar's landscape and the considered criteria for the accelerated development of the country.

According to the main participated variables, Qatar's landscapebased on ecological performance - is to be concluded within the framework processes.

\section{Ecological Landscape Indicators Based on Qatar National Vision 2030}

Building and urban development in the State of Qatar is taking place at an unprecedented rate. Such development is putting the environment at risk, threatening the ecosystem and biological diversity. While Qatar's authorities are currently formulating; legislation, regulatory bodies and management agencies for successful ecosystem management, the full implementation of these protective measures has not yet been developed. A lack of consideration of many of the variables in the early stages of the design process has resulted in a random final development project. The development needs not be in conflict with environment. In most cases Qatar already has the technology available to be much more efficient. What is often lacking is the political willpower to lead and the environmental assessment tools. In fact full implementation ultimately involves the cooperation of the; authorities (public and government) in line with the availability of the aforementioned tools.

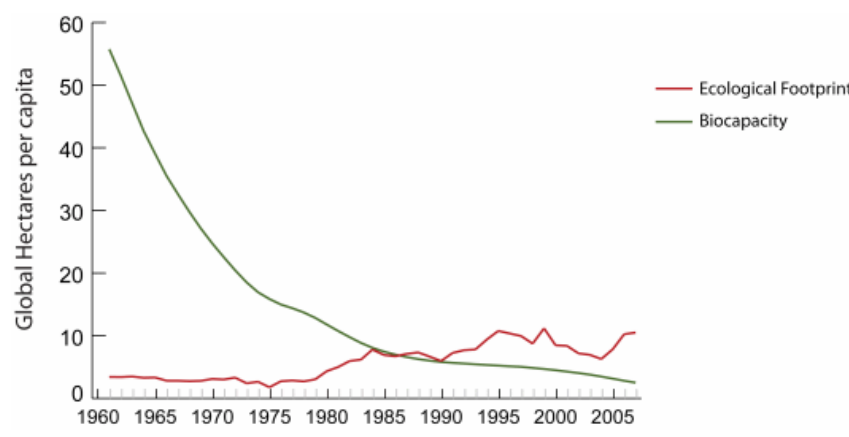

Figure 1: Per-Person Resource Demand (Ecological Footprint) and Resource Supply (Biocapacity) in Qatar since 1961.
According to Qatar National Vision 2030 [1], Qatar seeks to preserve and protect its unique environment. Development should be carried out with responsibility and respect, balancing the needs of economic growth and social development with the conditions necessary for environmental protection. The environmental pillar will be increasingly important as Qatar is forced to deal with local environmental issues; such as environmental degradation in addition to international environmental issues and the potential impact of global warming on water levels. Assessing the severity of risks and dealing with anticipated changes will require coordinated efforts to tackle problems that arise. An ecological landscape can be implemented in a timely fashion to ensure that current and future development projects support the country's goal of sustainable development.

The Qatar National Vision 2030 [1], was approved by Emiri Decision (44) for the year 2008. Qatar's National Vision rests on the balancing between four pillars; human, social, economic and environmental development as shown in figure 2. Development patterns often have negative effects on the natural environment. Environmental degradation can be reduced by avoiding rapid and unplanned development. It is also stated that the country must commit to making its future path of development compatible with the requirements of protecting and conserving the environment.

For environmental development outcomes, according to Qatar National Vision 2030, preserving and protecting the environment (including air, land, water and biological diversity) are to be through:

- An environmentally aware population that values the preservation of the natural heritage of Qatar and its neighboring States.

- An agile and comprehensive legal system that protects all elements of the environment, responding quickly to challenges as they arise.

- Effective and sophisticated environmental institutions that build and strengthen public awareness about environmental protection and encourage the use of environmentally sound technologies. These institutions will also conduct awareness raising campaigns, employ environmental planning tools and carry out environmental research.

In line with Qatar National Vision 2030 [1], the implemented ecological landscape indicators are considered as an important reference for the future development of the country.

\section{Ecosystem Classification: Variables And Framework- Case of Qatar}

According to the Planning Council [2], Qatar is developing a manageable system of sustainable development indicators for the country including; social, economic and environmental indicators. These indicators show clear trends in the aforementioned indicator areas, allowing decision-makers to measure the progress of the country with regards to what they view as the most important factors for such progress defining clear goals of the built environment would provide incentives for individuals, businesses and decision-makers.

Rowe and Sheard [3], conclude the aim of ecosystem classification is to provide primary information, on the biological and physical characteristics of various landscape components, in order to facilitate a range of interpretations and assist in sustainable management. Flynn and Francis [4], describe ecosystems through the integration of soils/ surficial geology, terrain, vegetation and climate patterns, Figure 3.

The ecological landscape framework process of Qatar has to be implemented according to three basic phases: 


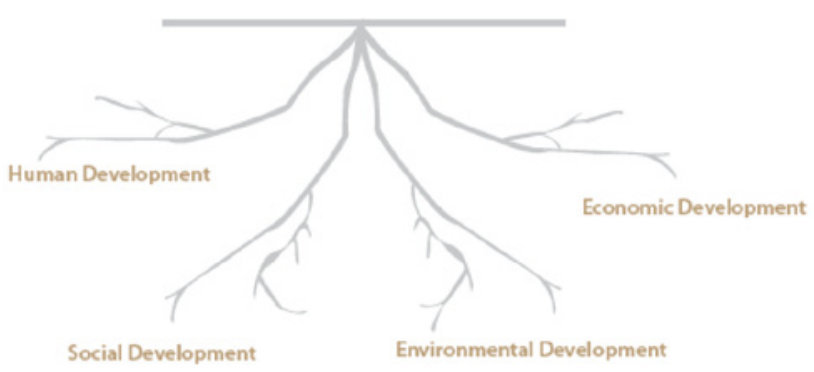

Figure 2: The four pillars of Qatar National Vision 2030 [1].

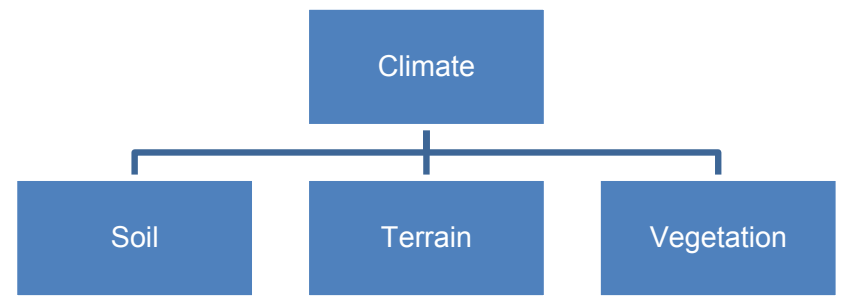

Figure 3: The integration of climate, soil, terrain and vegetation into an ecosystem unite.

- The first phase is to choose the policy issues and goals to be covered by the indicators. Awareness of the issues will depend on the best available information for the landscape management and to be based on the aim of Qatar National Vision 2030. The questions at this phase can guide the selection of policy issues for which indicators are relevant tools. This would give the most comprehensive overview of a country's ecosystem; therefore landscape plays an important role in the functioning of the ecosystem of Qatar.

- The second phase is developing indicators. Indicators are the prerequisite for adaptive landscape policies. They are needed to be well understood by policy makers and the public. Choosing indicators is the art of measuring as little as possible with the highest policy significance. A multi-indicator approach with complementary indicators is advisable and should be developed to show the various aspects of the ecological landscape. Indicators provide a general overview for policy making and form a communication for the public.

- The third phase is developing an appropriate mentoring program, which might be broader than the assessment of specified policy-related indicators in order to develop the evidence base. For example, it may be desirable to provide a warning of new phenomena or pressures at the early stage of landscape design, for which indicators have not been devised. In many cases, the immediate cost of action may appear high; however, the long-term costs of inaction may be even higher. Political commitment is indispensable to guarantee the continuity of any longterm monitoring programme. The monitoring program should also be standardized as much as possible, between different landscape ecosystem types and when measuring different variables.

Figure 4 shows the different phases of the framework, which provide guidance, indicators and monitoring for the developed landscape. It supports a strong sense to conserve the rich biodiversity and fulfills the needs of the region.

\section{Qatar ecosystem integrated variables}

As mentioned before, indicators are the prerequisite for adaptive landscape policies and part of the ecological landscape framework Ecological landscape indicators are abstractions of reality, which should provide insights into a better scenario to qualify the suitable solution for sustainable development. Landscapes have different land forms, vegetation types and land uses. The best way to envision an ecological landscape in any country is to look at the ecosystem integrated variables based on the characteristic of this country. The following is a description of these variables according to Qatar.

\section{Physical terrain and topographic features of Qatar}

The Qatari Peninsula is generally flat, figure 5a. Vegetation is extremely sparse along most of the Peninsula. In the southeast, near the large lagoon known as Khowr Al Udeid, figure 5b, there lies crescentshaped sand dunes (barchans) and salt flats. These features, known by their Arabic name sabkhat (singular, sabkha), are the remnants of saline lakes that have evaporated, leaving flat areas just above the water table marked by deposits of sand and gypsum, as well as salt. The area of Khowr Al Udeid presents a remarkable landscape formed by a globally unique combination of geological features.

Along parts of Qatar's eastern coast, north of the capital of Doha as shown in figure $5 \mathrm{c}$, Lie mangrove wetlands that is particularly valuable as breeding areas for many species of crustaceans and fish and as nesting areas for birds such as Herons and egrets. Unfortunately, Qatar's mangroves have suffered from overgrazing by camel herds, the reclamation of coastal tracts and seeps of oil from offshore wells. As of yet, there are no formally protected mangrove swamps in Qatar, although Qatar Petroleum, the state-owned oil and gas company, has initiated a mangrove conservation program [5].

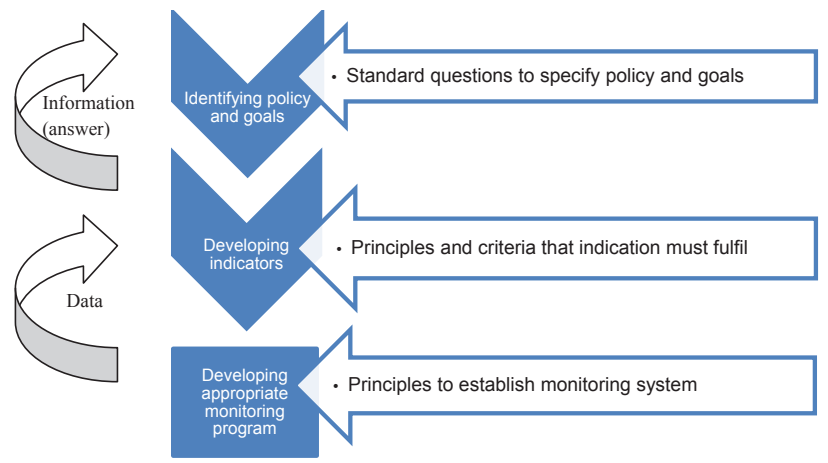

Figure 4: Main elements of the framework for national-level indicators and monitoring ecological landscape in Qatar.
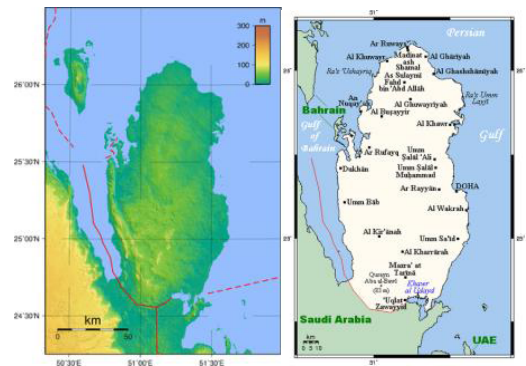

a) Topography of Qatar b) Khawr Al Udeid- Qatar $\quad$ c) Aerial view of Doha Figure 5: Physical Terrain of Qatar. 


\section{Climate of qatar}

Summer in Qatar (May to September) is extremely hot and dry. In July, average daytime highs reach $42^{\circ} \mathrm{C}\left(108^{\circ} \mathrm{F}\right)$ but could possibly hit highs of $50^{\circ} \mathrm{C}\left(122^{\circ} \mathrm{F}\right)[6]$. July and August are the most uncomfortable months because temperatures remain high and humidity increases [7]. Summer frequently brings the north winds from the north-northwest. In the winter and early spring, the north winds frequently accompany cold fronts. Qatar's climate transitions to winter during October, when the first post-summer showers (known as Wasmi) often occur. Annual precipitation in Qatar is quite low, with the large majority of it occurring between December and March [8]. Records from Doha International Airport show an average annual rainfall of just $75.2 \mathrm{~mm}$. When the infrequent rainfall finally comes, it often consists of short downpours that awaken dormant seeds in the desert soils, causing a brief flowering of plants. Winter weather in Qatar, in contrast to summer, is quite comfortable. From November through April, average daily temperatures rarely go below $16-21^{\circ} \mathrm{C}\left(61-70^{\circ} \mathrm{F}\right)$, with average high temperatures between $22-32^{\circ} \mathrm{C}\left(72-90^{\circ} \mathrm{F}\right)$ [9]. At night in the coldest winter months (December-February), temperatures frequently drop below $15^{\circ} \mathrm{C}\left(59^{\circ} \mathrm{F}\right)$ and can be chilly enough to warrant light jackets [8]. Table 1 shows: The high and low temperature, rainfall and rain days during the year for Qatar [10].

\section{Soil of qatar}

There is a common perception that the surfaces of the countries of the Gulf are comprised of materials in which plants will not grow. Abdulfatih, Adel, Alsubaey and Ibrahim [11] conclude that the soil classification of Qatar is commonly annexed to the seashores. Such soils locally called Sabkha varying grayish, brownish or bluish massive soils, having shallow to deep profiles from 30 to $150 \mathrm{~cm}$ depth. Their texture is between calcareous clay loam, sandy clay loam and sandy loam. Salt crusts are observed on soil surfaces, especially in places where the topsoil goes through a prolonged dry period. This soil association covers approximately 70000 hectares, equivalent to $6 \%$ of the Qatari soil.

Figure 6 is an illustration of the landscape around Dukhan on the west of the peninsula showing how erosion has shaped the limestone rock formations, undercutting the softer stones, leaving the harder top stones projecting. Wind and water are the main causes of soil erosion. Soil Erosion is the process of weathering and transporting of solids (sediment, soil, rock and other particles) in the natural environment or their source and depositing them elsewhere. This concept of a barren peninsula is obviously not so, though it is true that the top soil is unable to support much planting due to its character, depth and the lack of water.

\section{Vegetation of qatar}

It appears that plant distribution in Qatar is partially determined by plant-soil-water relationships. Location of Qatar, being a part of the large land mass of the Arabian Peninsula, plays an essential role in the makeup of its flora and vegetation. Ephemerals, dwarf woody perennials, few tree species and perennial grasses are the most common features of plant life forms in the inland leveled parts of the country. The sandy soils of Sabkhas and sand dunes support the poorest plant cover, at the same time, certain species attain high relative importance value indices only in sand dunes and Sabkhas and their growth is more or less confined to such sandy habitats such as Cyprus conglomerates var. It also appears that there is a close interaction between the poor vegetation cover and the continuous sand movement due to the strong North and North West prevailing winds. Generally the inland vegetation is sparse, with vast areas either barren or with few sporadic species. However, well established plant communities grow in depressions and water catchment areas. Figure 7 shows some examples of plants in Qatar.

\section{Developing Ecological Landscape Indicators for Qatar}

This part is to develop the significant ecological landscape indicators in Qatar. It begins by implementing the underlying requirements and then considers baseline information that is likely to be available to local authorities. It will be necessary to apply the locally developed relevant indicators in the absence of national standards which are under development. The landscape's ecological indicators for Qatar are to include five main variables as follows:

\section{Analyzing the existing landscape's structures}

It is particularly important to consider the impact of the Landscape's structures as an indicator for landscape performance in Qatar. The knowledge of Landscape's structures is very important for the planning action because it is possible to have indications about the urban sensibility of the different land parts in the future. It includes the amount of forest or wetland, the length of forest edge, or the density of roads can be aspects of landscape composition. Structure is determined by the composition, the configuration and the proportion of different patches across the landscape. In Qatar, it is important to connect the landscape structure with the built area to draw the complete image of the urban pattern. This point should be considered to qualify the integration between both; Figure 8 shows different landscape structure in Doha- Qatar.

\section{Establishing the landscape's cultural value}

Cultural landscapes are areas that include cultural and natural resources associated with an historic event, activity, person, or group of people. They also exist in relation to their ecological contexts such as: biological, esthetical and economical contexts. In Qatar, this aspect gives weight to an underappreciated history while remaining firmly pointed toward the future. It shows an awareness of the speed with which contemporary cultures change. To satisfy the ecological landscape in

\begin{tabular}{|c|c|c|c|c|c|c|c|c|c|c|c|c|}
\hline Month & Jan & Feb & Mar & Apr & May & Jun & Jul & Aug & Sep & Oct & Nov & Dec \\
\hline High Temp ${ }^{\circ} \mathrm{C}$ & 22 & 23 & 26 & 31 & 38 & 40 & 41 & 40 & 38 & 35 & 29 & 24 \\
\hline High Temp ${ }^{\circ} \mathrm{F}$ & 72 & 73 & 79 & 88 & 100 & 104 & 106 & 103 & 100 & 95 & 83 & 75 \\
\hline Low Temp ${ }^{\circ} \mathrm{C}$ & 13 & 13 & 16 & 21 & 24 & 27 & 29 & 28 & 26 & 23 & 19 & 15 \\
\hline Low temp ${ }^{\circ} \mathrm{F}$ & 55 & 55 & 61 & 71 & 76 & 81 & 84 & 83 & 79 & 73 & 66 & 60 \\
\hline Rainfall $(\mathrm{mm})$ & 13 & 17 & 16 & 9 & 3 & 0 & 0 & 0 & 0 & 1 & 1 & 4 \\
\hline Raindays & 4 & 4 & 5 & 4 & 1 & 0 & 0 & 0 & 0 & 1 & 1 & 4 \\
\hline
\end{tabular}


Citation: Ibrahim HGA (2012) Descriptive Ecology Approaches to an Urban Landscape in Qatar. J Ecosyst Ecogr 2: 119. doi:10.4172/21577625.1000119

Page 5 of 7

Qatar, it must emphasize the culture dimension of the country so that it can be more effective when interacting with the urban. Figure 9 gives an example of establishing the cultural value within the landscape as a part of the design process of Museum of Islamic Art, Doha- Qatar.

\section{Landscape and social integration}

This step is intended to guide and structure the implementation of landscape integration by facilitating their social acceptability. It is not a required standard but rather an objective which developers should strive to attain, while ensuring adaptability to the characteristics of the environment concerned (physical, biological, cultural and human). Landscapes have always been in transition with changing demographics and community attitudes. The urban development in Qatar is mostly connected with political, social, educational and other events that the landscape should reflect. The analysis of the landscape, based on social interaction, is an important aspect to be considered as an indicator to measure the landscape ecology. Figure 10 shows landscape elements illustrating Qatar as a State of educational vision and ideology.

\section{Landscape dynamics}

The dynamic is the result of complexity and has tremendous importance for most living organisms. For this purpose fractal analysis seems a very promising tool that justifies the dynamicity in landscape design. Landscapes, like other natural systems, can behave differently when affected by natural or human-induced stress. The dynamic of the landscape depends on some major factors including: disturbance frequency, rate of recovery from disturbance and the size of the disturbance events. The landscape dynamic applies factors those brought on by human intervention as well as those caused by nature. The best example of landscape dynamics in Qatar is Pearl Qatar in Doha, figure 11.

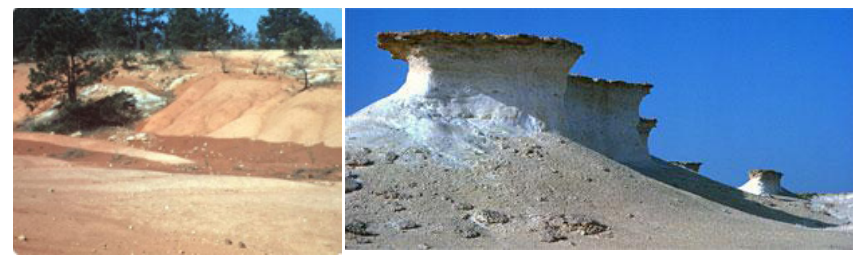

Figure 6: Soil erosion: Landscape character on the west of Qatar.

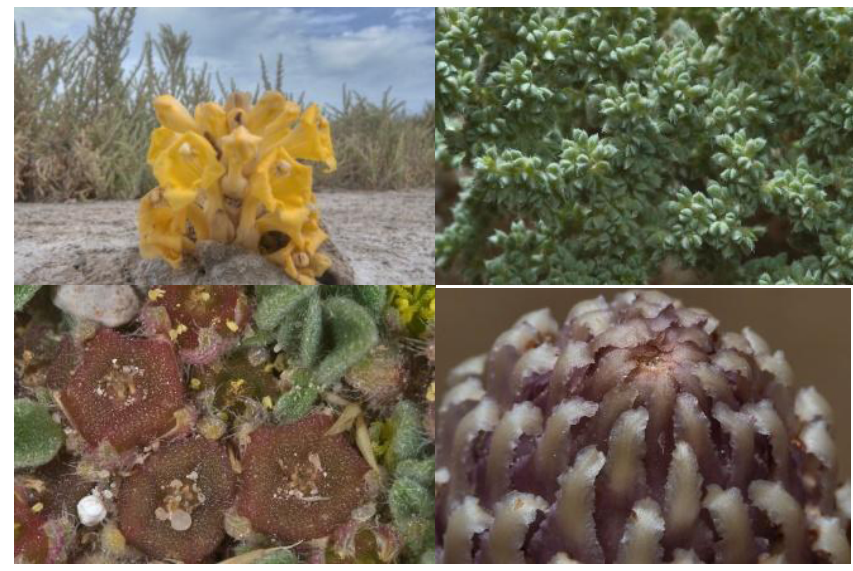

${ }^{2} \mathrm{http}: / /$ www.asergeev.com/pictures/k/Desert_plants_in_Qatar.htm

Figure 7: Plants that grow in Qatar'.

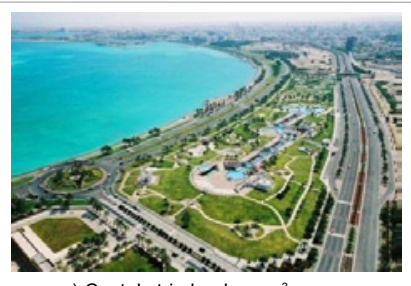

a) Costal strip landscape ${ }^{3}$

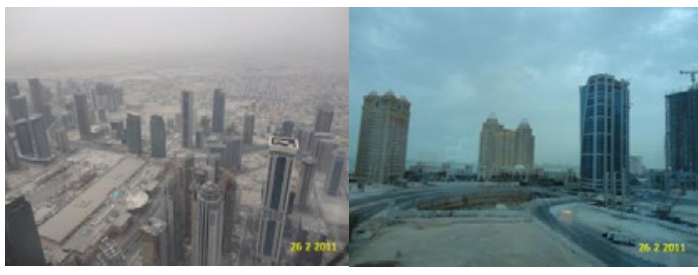

b) $)^{4}$ and

c) ${ }^{5}$ Unclear landscape structure

${ }^{3}$ http://usak-isro.blogspot.com/2011/01/banks-in-doha-qatar.html ${ }^{4}$ http://www.panoramio.com/photo/49557412 ${ }^{5} \mathrm{http}: / /$ www.panoramio.com/photo/49557781

Figure 8: Landscape structure in different areas of Doha- Qatar.

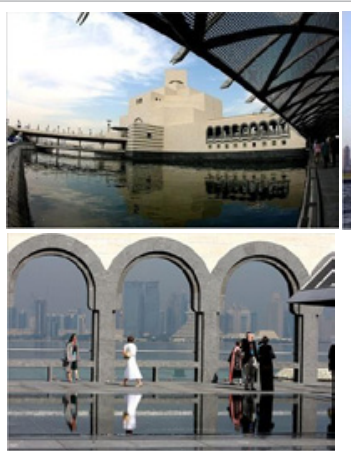

${ }^{6} \mathrm{http}: / /$ www.wayfaring.info/2008/11/25/museum-of-islam-art/

Figure 9: Landscape and the positioning of the Museum of Islamic Art as a catalyst for the development and demonstrates the vision and the culture dimension of Qatar ${ }^{6}$.

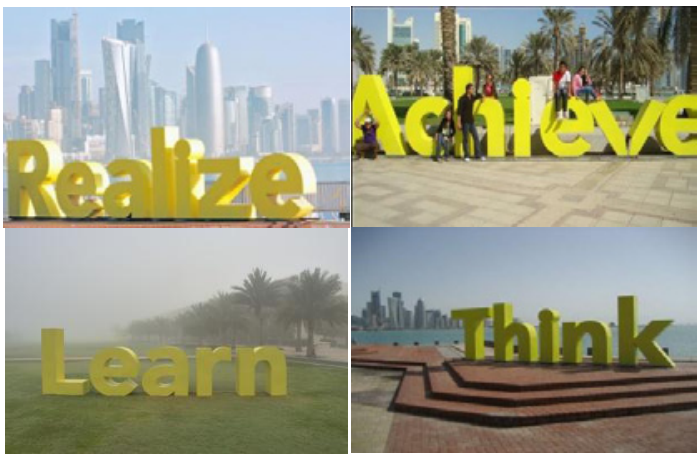

Figure 10: Landscape elements conclude Qatar as a knowledgeable country.

\section{Landscape based function}

Landscape function refers to how each element in the landscape interacts based on its life-cycle events. Considering the functional use of plants, as an example, which have been used for beautification due to their aesthetic qualities. The expression "functional use of plants" as one 
of the landscape elements helps to explain that they can perform other functions in the landscape. Plants have design qualities such as form, color, texture and mass. More recently, the functional characteristics of plants have been recognized. Figure 12 shows examples of the way that plants can be used functionally [12]. However, the cultivation of plants necessitates demands upon the landscape specification.

\section{Indicators for an Ecological Landscape in Qatar: Implementation Stage}

The analysis and evaluation of landscape demands has implemented indicators for the second phase of the framework as shown in figure 4 . These indicators are measuring the present situation of landscapes and are also used in data sets to define ecological value. The implemented framework in figure 13 is driven by the strategic perspectives of the Qatar National Plan 2030.

The implemented framework has concluded in five main phases in sequence and includes: Landscape Analysis; Identify Policy and Goals; Ecological Landscape Indicator; Landscape-Based Indicator Evaluation and Developing Appropriate Monitoring Program. The definition of each phase is to be illustrated as follows:

\section{Landscape analysis}

This phase shows the landscape design criteria including; concept, development and design of the ecological aspects. The purpose of this stage is to expand the concept of the landscape level. This is an approach and techniques to be developed for measuring landscape performance in Qatar. The analysis discusses some broad issues affecting when and how landscape-level analysis might be used. It gives a detailed breakdown of how landscape elements are conducted and the usefulness of the landscape organization.

\section{Identify policy and goals}

The reference in this stage is the authority's policy and goals (4 Pillars) in Qatar National Plan 2030 shown in figure 2. The policy and

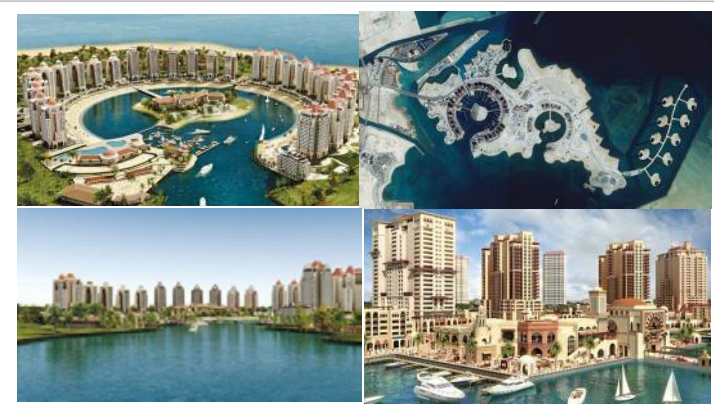

Figure 11: The Pearl, a 985-acre man-made island boasting golden-sand beaches, yacht-filled marinas, glitzy retail outlets and showrooms.

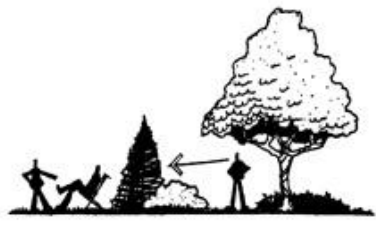

a) Plants may be used architecturally to form walls, canopies or floors.

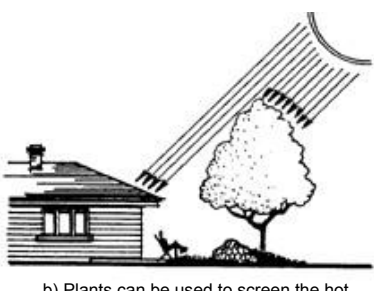

b) Plants can be used to screen the ho summer sun while allowing sunlight of climate control
Figure 12: Examples of plant functions [12] goals are based on; economic, human, environmental and cultural development pillars. This will encourage analytical and critical thinking, as well as creativity and innovation of the landscape. It will promote social cohesion and respect for Qatari society's values.

\section{Ecological landscape indicator for Qatar}

The implemented ecological landscape in the last section comes as a third stage of the framework. These indicators are set up to assess the landscape design according to the ecological variables. The benefit of this stage is to examine the effect of the landscape characteristics on the ecosystem benefits in Qatar. The determinants of the ecosystem benefits are a function of both onsite characteristics (e.g., the ecological quality of the site) and a function of the landscape context in which sites reside. The qualifying of this stage reflects the understanding that ecosystem functions according to the surrounding ecological landscape.

\section{Landscape-based indicator evaluation}

This stage reviews existing landscape indicators developed and accordingly assesses the landscape design based on these indicators. It provided a conclusion about the rank of the landscape design related to the developed indicators. The rank of landscape- indicators can be established by the significance of the considered design critical factors.

\section{Developing appropriate mentoring program}

Landscape management is an important stage in the design process. Several important considerations should be made in the development of a monitoring plan. These include considering the impact of monitoring on the biodiversity, feedback about the effectiveness of the management and how the landscape mentoring program will qualify the guidance during the process. In developing the monitoring plan, it is important to consider how to minimize the impact monitoring has on the habitat. For example, arrangements should be made for the cleanup and removal of materials and equipment used to collect data.

\section{Conclusion and Discussion}

Many countries have taken a rather proactive approach towards implemented indicator-based landscape assessments. They have developed more refined methodologies in terms of national policy orientation. This is resulting in an impressive monitoring of sustainable development. In Qatar, landscape-indicator values are clearly less apparent. There must be a targeted approach towards landscape indicator-based ecological dimensions, with an existing framework assessment, which provides a sustainable urban development.

Sustainable is at the heart of the Government's drive towards an urban renaissance. The Government of Qatar set out pillars in Qatar's National Plan, which are to be considered; human, social, economic and environmental values. In response to this, it is required to develop urban development assessment tools or indicators for measuring different ecological variables for the landscape design. These indicators create or reinforce local urban distinctiveness and they should:

a) Consider the direct and indirect impacts on the natural environment.

b) Be aesthetically appealing as a result of good architecture and appropriate landscape design.

c) Ensure that developers and their agents are aware of the extreme importance of the external aspects of development, as defined by relevant Local Plan policies and implement the requirements of these policies appropriately. 


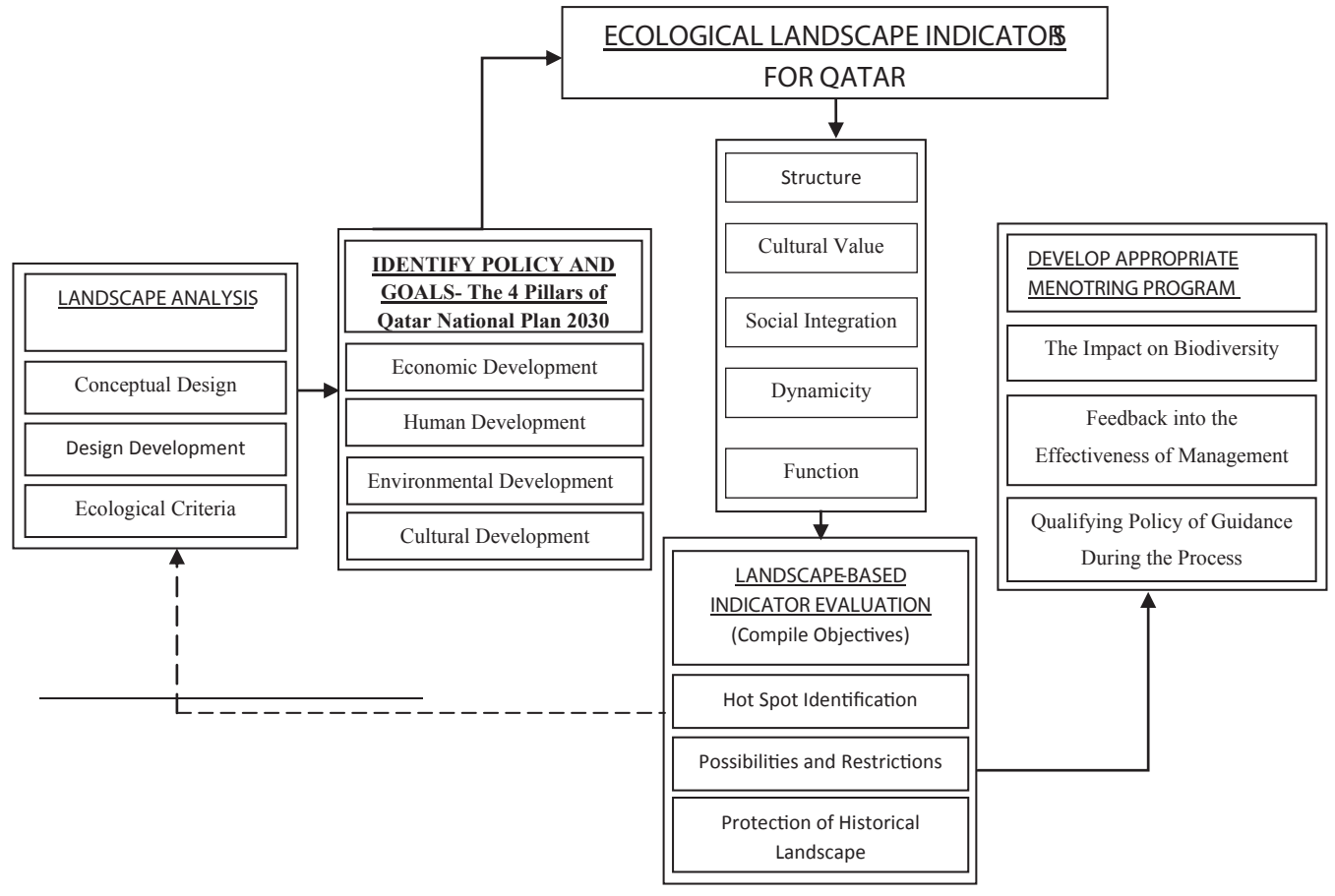

Figure 13: Implementing ecological indicators into the ecological framework in Qatar

d) Ensure that all appropriate information is submitted and clearly presented as part of the planning process, thus avoiding unnecessary and potentially costly delays.

e) Improve the quality of the environment in areas undergoing change.

In this paper, the ecological indicators for the landscape in Qatar are implemented to be a part of the landscape assessment framework. It addresses questions about the landscape features that have been raised. It also provides a general scientific assessment for planning and managing landscape contexts. Generally, a fundamental objective is how best to minimize the impact of the landscape proposal on the surroundings and in the longer term, enhance the landscape in terms of overall appearance, amenity/recreational and environmental objectives.

In future, the concluded framework needs to be developed to categorize the performance of the proposed landscape. This leads to produce a new approach in scoring techniques. Interpretation of the framework should be conducted involving a team of experts. A team, comprising of a Planner, Landscape Ecologist, Conservationist, Hydrologist, Civil Engineer, Geologist and Socio-Economic Scientist, should be recruited. Later on, all data needs to be interpreted and translated into ranked criteria- based on thesustainable principals. It is also important to apply GIS database analysis focusing on the resulting Ecological score.

\section{References}

1. Qatar National Vision 2030 (2008) General Secretariat for Development Planning (GSDP).

2. Planning Council: Sustainable Development Indicators in Qatar (2006) The Planning Council-General Secretariat.

3. Rowe JS, Sheard JW (1981) Ecological land classification: a survey approach Environ Manage 5: 451- 464
4. Flynn N, Francis S (2011) The Yukon Ecosystem and Landscape Classification (ELC) Framework: Overview and Concepts, Interim Draft for Review, Yukon ELC Working Group.

5. Qatar in Perspective (2010) An Orientation Guide, technology integration division, Defense Language Institute Foreign Language Center (DLIFLC).

6. Encyclopedia Britannica Online (2010) Qatar: Land, Climate.

7. Qatar Tourism Authority (2009) Climate.

8. World Meteorological Organization (2010) Climatological Information.

9. Cultures of the World (2008) Qatar, Orr, Tamra, "Geography: A Hot, Arid Climate, Tarrytown, NY: Marshall Cavendish Benchmark: 10-11.

10. Embassy of State of Qatar (2010) Geography and Climate.

11. Abul Fatih HA, Adel Bari EM, Alsubaey A, Ibrahim YM (2002) Halophytes and soil salinity in Qatar, Qatar University Science Journal 22: 119-135.

12. Sydnor TD (1994) Functional Uses of Plants in the Landscape, Ohio State University Fact Sheet, Horticulture and Crop Sciences, 2001 Fyffe Court, Columbus, $\mathrm{OH} 43210$

Submit your next manuscript and get advantages of OMICS Group submissions

Unique features:

- User friendly/feasible website-translation of your paper to 50 world's leading languages

Audio Version of published paper

Digital articles to share and explore

Special features:

200 Open Access Journals

15,000 editorial team

21 days rapid review process

Quality and quick editorial, review and publication processing

Indexing at PubMed (partial), Scopus, DOAJ, EBSCO, Index Copernicus and Google Scholar etc

Sharing Option: Social Networking Enabled

- Authors, Reviewers and Editors rewarded with online Scientific Credits

Better discount for your subsequent articles

Submit your manuscript at: http://www.omicsonline.org/submission 